\title{
The 3D nuclear conformation of the major histocompatibility complex changes upon cell activation both in porcine and human macrophages
}

Florence Mompart ${ }^{1}$, Alain Kamgoué ${ }^{2}$, Yvette Lahbib-Mansais ${ }^{1}$, David Robelin ${ }^{1}$, Agnès Bonnet ${ }^{1}$, Claire Rogel-Gaillard $^{3}$, Silvia Kocanova ${ }^{2}$ and Martine Yerle-Bouissou ${ }^{1 *}$

\begin{abstract}
Background: The crucial role of the major histocompatibility complex (MHC) for the immune response to infectious diseases is well-known, but no information is available on the 3D nuclear organization of this gene-dense region in immune cells, whereas nuclear architecture is known to play an essential role on genome function regulation. We analyzed the spatial arrangement of the three $\mathrm{MHC}$ regions (class I, III and II) in macrophages using 3D-FISH. Since this complex presents major differences in humans and pigs with, notably, the presence of the centromere between class III and class II regions in pigs, the analysis was implemented in both species to determine the impact of this organization on the 3D conformation of the MHC. The expression level of the three genes selected to represent each MHC region was assessed by quantitative real-time PCR. Resting and lipopolysaccharide (LPS)-activated states were investigated to ascertain whether a response to a pathogen modifies their expression level and their 3D organization.
\end{abstract}

Results: While the three MHC regions occupy an intermediate radial position in porcine macrophages, the class I region was clearly more peripheral in humans. The BAC center-to-center distances allowed us to propose a 3D nuclear organization of the MHC in each species. LPS/IFNy activation induces a significant decompaction of the chromatin between class I and class III regions in pigs and between class I and class II regions in humans. We detected a strong overexpression of TNFa (class III region) in both species. Moreover, a single nucleus analysis revealed that the two alleles can have either the same or a different compaction pattern. In addition, macrophage activation leads to an increase in alleles that present a decompacted pattern in humans and pigs.

Conclusions: The data presented demonstrate that: (i) the MHC harbors a different 3D organization in humans and pigs; (ii) LPS/IFNy activation induces chromatin decompaction, but it is not the same area affected in the two species. These findings were supported by the application of an original computation method based on the geometrical distribution of the three target genes. Finally, the position of the centromere inside the swine MHC could influence chromatin reorganization during the activation process.

\footnotetext{
* Correspondence: martine.bouissou-matet@inrae.fr

'GenPhySE, Université de Toulouse, INRAE, ENVT, 1388 GenPhySE, 24 Chemin

de Borde Rouge, 31326 Cedex Castanet-Tolosan, France

Full list of author information is available at the end of the article
}

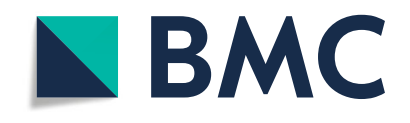

(c) The Author(s). 2021, corrected publication 2021. Open Access This article is licensed under a Creative Commons Attribution 4.0 International License, which permits use, sharing, adaptation, distribution and reproduction in any medium or format, as long as you give appropriate credit to the original author(s) and the source, provide a link to the Creative Commons licence, and indicate if changes were made. The images or other third party material in this article are included in the article's Creative Commons licence, unless indicated otherwise in a credit line to the material. If material is not included in the article's Creative Commons licence and your intended use is not permitted by statutory regulation or exceeds the permitted use, you will need to obtain permission directly from the copyright holder. To view a copy of this licence, visit http://creativecommons.org/ licenses/by/4.0/. The Creative Commons Public Domain Dedication waiver (http://creativecommons.org/publicdomain/zero/1. 0/) applies to the data made available in this article, unless otherwise stated in a credit line to the data. 
Keywords: Nuclear architecture, Gene expression, Major histocompatibility complex, Macrophage, LPS/IFNY activation, 3D-FISH

\section{Background}

The immune system plays a central role in mammals, not only in health maintenance but also in pathogenesis. There are several ways of protecting a human or an animal against invasion by pathogens. The first line of defense is provided by an innate immune response consisting of barriers such as skin, tears, saliva and mucus, as well as an inflammatory response. This is closely followed by defensive mechanisms due to adaptive immune responses that include both a humoral response produced by antibodies, and a cell-mediated response produced by $\mathrm{T}$ cells that have the ability to destroy other cells. The immune system also includes other key antiinfectious actors that are able to destroy infectious agents, known as phagocytic cells, such as monocytederived macrophages [1] and neutrophils [2]. Neutrophils are the first cells to intervene at infection sites but have a short lifespan and are taken over by monocytes that differentiate into macrophages and phagocyte both pathogens and apoptotic neutrophils. To do this, these immune cells undergo a series of distinct functional changes both at the cytoplasm and nucleus levels. Most of these changes imply variations in gene expression revealed by transcriptomic analyses [3].

The cell-mediated adaptive immune response is regulated by the major histocompatibility complex (MHC). The MHC it is one of the most gene-dense regions in mammals and has been divided into three regions referred to as class I, II and III [4]. The class I and class II regions include histocompatibility genes that encode proteins involved in the adaptive immune response, through their respective presentations of endogenous and exogenous peptide antigens, to circulating $\mathrm{T}$ lymphocytes [5]. The class III region comprises many important immune-defense genes such as the tumor necrosis factor gene families and components of the complement cascade. In humans, this complex (HLA Human Leucocyte Antigen) resides in the short arm of chromosome 6 and spans over 3.6 Mb [6]. In pigs, the MHC complex, or swine leukocyte antigen (SLA), is located on chromosome 7 (SSC7) [7] and spans between 2.4 and $2.66 \mathrm{Mb}$, depending on the haplotype [8]. The class I and class III regions are located on SSC7p1.1, while the class II region is located on SSC7q1.1 [9]. This physical assignment of the swine MHC spanning the centromere of SSC7 is unique among mammals studied to date. The SLA class I, class III and class II regions were found to span approximately $1.06 \mathrm{Mb}, 0.67 \mathrm{Mb}$ and $0.46 \mathrm{Mb}$, respectively (Scrofa11.1 assembly), making the swine MHC the smallest among mammalian MHC examined so far. Over 150 loci have been identified in the entire SLA region, and at least 121 genes are predicted to be functional [10] and are reviewed in [8]. The SLA reference sequence comprises the entire class I, class II, and class III regions, and a BAC contig that covers the entire region with the exception of the centromere has been built $[10,11]$.

Numerous studies have shown that chromatin is organized into hierarchical 3D structures that are thought to play a role in gene regulation [12-14]. Insights into the functions and 3D structures of genomes have been mainly derived from microscopy techniques such as 3D fluorescence in situ hybridization (3D FISH), molecular approaches including chromosome conformation capture technologies (3C and its derivatives) and, more recently, ligation-free methods (reviewed in [15]). As of this time, the spatial distribution of the genome is explored at the genome-wide scale by high-throughput chromosome conformation capture $(\mathrm{Hi}-\mathrm{C})$ that provides genome-wide maps of contact frequencies [16]. However, these methods performed on populations of millions of cells give an average view of what is happening in the cell population. Single-cell Hi-C experiments and super-resolution imaging [17-20] and, more recently, $\mathrm{Hi}-\mathrm{C}$ combined with high-throughput fluorescence in situ hybridization (hiFISH) [21], have revealed the high degree of cell-to-cell and allele-to-allele heterogeneity in spatial genome organization, emphasizing the benefits of combining single-cell and cell population approaches.

The position of single genes within the nucleus has been widely investigated. While their non-random positioning has been largely demonstrated, the link with their functional status is still being debated [22, 23]. Similarly, a link between relative gene position within a chromosome territory (interior: less active or repressed; exterior or looped out: more active), and transcription has been established in numerous studies [24-27]. In this context, we previously investigated the spatial arrangements of genes differentially expressed (up- and down-regulated) in porcine macrophages when the immune cells are activated by LPS (lipopolysaccharide)/ IFN $\gamma$ [28]. Our results demonstrated that there is not a systematic relocalization of these genes in the nuclear space. Three of the four up-regulated genes relocalized in the nucleus and/or relative to their chromosome territories $(\mathrm{CT})$, while the four down-regulated genes did not change their positions. We found the same results in neutrophils, another type of immune cell, but not in 
fibroblasts, except for TNF $\alpha$, which retains its tendency to be at the edge or outside of its CT in the three cell types tested. These results suggest that relocalization of genes differentially expressed in response to LPS/IFN $\gamma$ activation is gene- and cell type-specific, as well as being closely linked to the entire up-regulation status of their chromosomal regions [28]. TNF $\alpha$ is located in a region of prime importance for the immune response since it contains the MHC. However, no information is available on the 3D organization of this particular and important region.

In the present study, we focused our analysis on this region to investigate its $3 \mathrm{D}$ conformation in macrophages. In terms of physical organization, the human and porcine MHCs harbor an important difference due to the presence of the centromere inside the complex in swine where it separates the class II from the class III region. The analysis was done on both porcine and human macrophages to determine if this particular organization in swine has an impact on the 3D conformation of the $\mathrm{MHC}$ and on its plasticity. We also investigated whether this conformation changes when macrophages are activated by LPS/IFN $\gamma$. To address these questions, we selected Bacterial Artificial Chromosomes (BACs) containing genes that map to each of the three MHC regions in humans and pigs in order to examine their spatial arrangement. This was performed by 3D-FISH on structurally preserved macrophages in combination with confocal microscopy and 3D image analyses. The expression of the three genes selected to represent each MHC region was assessed by quantitative real-time PCR in resting and activated macrophages to ascertain whether a response to a pathogen aggression modifies the expression level of the selected genes and the 3D organization of the complex. Finally, we assessed 3D folding of the MHC by application of a mathematical approach that allowed us to confirm our observations.

\section{Results}

\section{Selection of BACs containing MHC genes}

In order to investigate the $3 \mathrm{D}$ nuclear organization of the MHC in macrophages and to analyze the effects of LPS/IFN $\gamma$ activation on both, the nuclear organization and the expression of target genes, we selected BACs containing genes specific to each $\mathrm{MHC}$ region in pigs and in humans. Comparative analysis of the MHC in mammalian species has revealed some species-specific features, the most notable being the size of the class I region, which is almost two times bigger in humans (1.89 $\mathrm{Mb})$ compared to pigs (1.06 Mb) (Fig. 1), and the position of the centromere that interrupts the SLA complex between class III and II regions, whereas it is outside in the HLA complex. However, there are also large regions of shared syntenies and sequence conservation between the SLA and the HLA complex [10] that have facilitated the choice of the homologous genes representative of each MHC class. We selected SLA-1 and HLA-A based on their genomic positions and functionality as classical class I genes, TNF $\boldsymbol{\alpha}$, the master regulator of inflammatory cytokine production in both species for the MHC
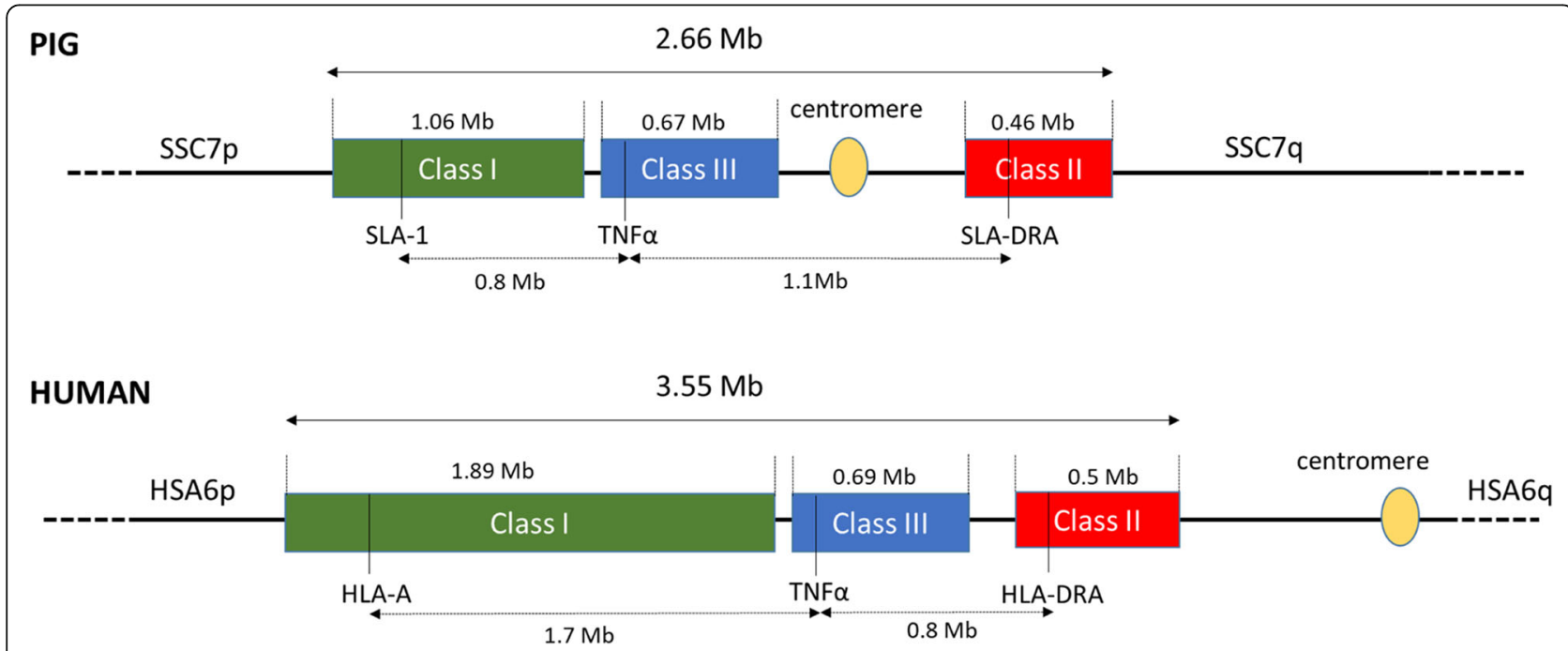

Fig. 1 Comparative genomic organization of the swine and the human major histocompatibility complex (MHC). The genes that were used in this study to represent each MHC region are indicated with their relative position in their corresponding class. The swine leucocyte antigen (SLA) class I and III regions reside on the short arm of chromosome 7 (SSC 7: Sus scrofa 7) and are separated from the class II region located on the long arm by the centromere. The genomic distances are those reported in [8] and are taken from the swine genome assembly 11.1. The human leucocyte antigen (HLA) complex resides on the short arm of chromosome 6. The genomic distances are taken from the human genome assembly GRCh38.p13 
class III region and, finally, SLA-DRA and HLA-DRA involved in peptide presentation to $\mathrm{CD} 4 \mathrm{~T}$ cells for the MHC class II region (Fig. 1). The presence of the genes in the BAC clones selected for the FISH experiments was verified by PCR, and the chromosomal locations of all BACs were controlled by 2D-FISH on metaphase spreads, both in porcine and in human cells. As expected, the BACs containing SLA-1 (class I region) and TNF $\boldsymbol{\alpha}$ (class III region) were found on the short arm of porcine chromosome 7 (SSC7p), and the BAC containing SLA-DRA (class II region) mapped to the long arm (SSC7q), while the three BACs containing the human genes were found on the short arm of human chromosome 6 (HSA6p) (Table 1; Additional file 1: Fig. S1).

\section{Radial positioning of class-specific MHC genes}

To first determine the localization of the MHC in the macrophage nuclei, we hybridized the BACs specific to the three MHC regions in 3D-FISH experiments on structurally preserved porcine and human macrophages. For the purpose of simplification, the BAC probes will be designated by the gene chosen to represent each MHC region. Figure 2 provides examples of typical patterns observed in porcine (Fig. 2a) and human (Fig. 2b) macrophage nuclei after hybridization with the MHC probes. After each 3D experiment, we acquired serial optical sections using confocal microscopy from around 60 to 88 nuclei (see Methods). Images were processed with NEMO software [29]. Distances between the probe signal centers and the nucleus center were measured for the three selected genes and were individually normalized to the nucleus radius of each cell to enable comparisons between different nuclei. Cumulative frequency graphs of the radial positions for each gene in porcine and human macrophages demonstrated their nonrandom radial nuclear organization (Fig. 2c-d). No difference in radial positioning was observed between the three genes in porcine marcophages (Fig. 2c). We observed that the genes tend to occupy an intermediate position. The results are quite different in human macrophages since HLA-DRA (class II) and TNF $\alpha$ (class III) both occupy an intermediate position, whereas HLA-A (class I) shows a significantly more peripheral position (Fig. 2d). These results suggest that the HLA and SLA complexes probably have a different 3D organization.

\section{Gene-to-gene distances in the MHC and spatial organization}

In order to study the 3D organization of the MHC in both species, we measured the 3D interprobe distances:

(i) SLA-1/HLA-A (class I)-SLA-DRA/HLA-DRA (Class II) distance, denoted a; (ii) SLA-DRA/HLA-DRA (class II)-TNF $\alpha$ (class III), denoted b; and (iii) SLA-1/HLA-A (class I)-TNF $\alpha$ (class III), denoted c (Fig. 3a). We normalized each measured distance to the nucleus diameter of each cell to allow comparisons between cells. In addition, using these 3D measurements, we calculated all the internal angles (Fig. 3a; Additional file 2: Table S1). We observed that in resting porcine macrophages, the distances $\mathrm{a}$ and $\mathrm{b}$ are equal, and the distance $\mathrm{c}$ is

Table 1 Primers for BAC clones verification by PCR and for $\mathrm{QPCR}$ experiments

\begin{tabular}{|c|c|c|c|c|}
\hline $\begin{array}{l}\text { Target genes } \\
\text { (MHC Class) }\end{array}$ & Localization & Primer sequences & 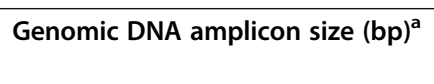 & $\begin{array}{l}\text { cDNA Amplicon size (bp) } \\
\text { (Accession numbers) }\end{array}$ \\
\hline \multirow[t]{2}{*}{ SLA-1 (I) } & SSC 7p1.1 & TGGTGGCTGGAGTTGTGATC & 515 & 66 (NM_001097431) \\
\hline & & CCTGAGTGTAGCTCCCTCCT & & \\
\hline \multirow[t]{2}{*}{ SLA-DRA (II) } & SSC 7q1.1 & CCCTCAACCGAGGATGTCTA & 432 & 126 (NM_001113706) \\
\hline & & AGCACACACGGTGTTCTCTG & & \\
\hline \multirow[t]{2}{*}{ TNFa (III) } & SSC 7p1.1 & ACTGCACTTCGAGGTTATCGG & 887 & 118 (NM_214022) \\
\hline & & GGCGACGGGCTTATCTGA & & \\
\hline \multirow[t]{2}{*}{ B2M } & SSC 1q1.7 & TCATCCAACCCAGATGCA & 1733 & 162 (NM_213978) \\
\hline & & TTCTACCTTCTGGTCCACACTGA & & \\
\hline \multirow[t]{2}{*}{ HLA-A (I) } & HSA 6p22.1 & TACAACCAGAGCGAGGC & 373 & $132\left(N M \_002116\right)$ \\
\hline & & CTCGTTCAGGGCGATGTAAT & & \\
\hline \multirow[t]{2}{*}{ HLA-DRA (II) } & HSA 6p21.32 & СCCTCAACTGAGGACGTTTA & 393 & 105 (NM_019111) \\
\hline & & AGTCTCTGGGAGAGGGCTTG & & \\
\hline \multirow[t]{2}{*}{ TNFa (III) } & HSA 6p21.33 & GCTGCACTITGGAGTGATCG & 916 & 123 (NM_000594) \\
\hline & & TGGGCTACAGGCTTGTCACT & & \\
\hline \multirow[t]{2}{*}{ B2M } & HSA 15q21.1 & TACACTGAATTCACCCCCACTG & 2020 & 143 (NM_004048.2) \\
\hline & & TCCAATCCAAATGCGGCATC & & \\
\hline
\end{tabular}



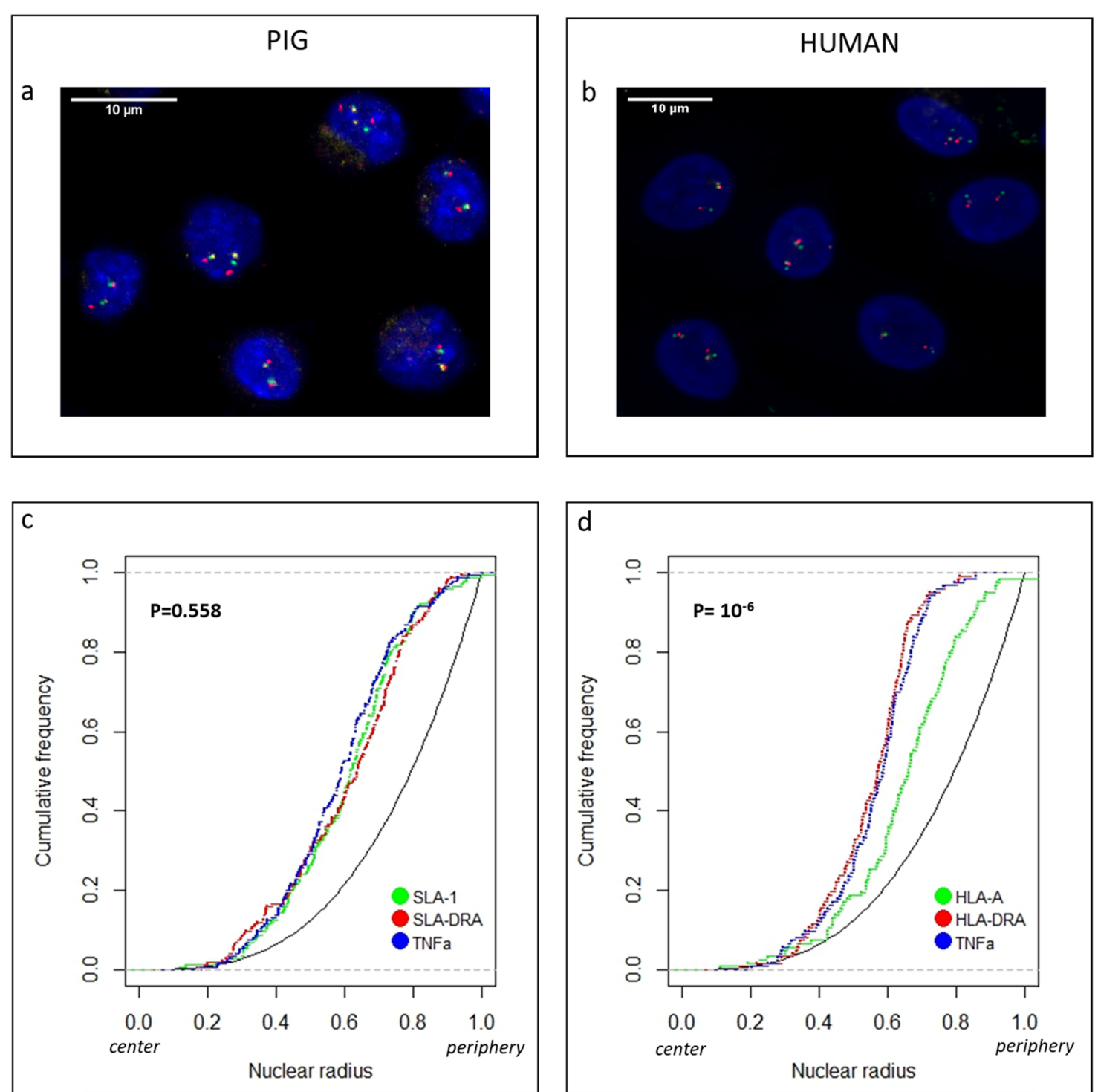

Fig. 2 a-b Maximum intensity projections of confocal stacks of 3D-FISH experiments carried out with the three BAC probes representative of each $\mathrm{MHC}$ region co-hybridized on structurally preserved porcine (a) and human (b) macrophage nuclei: BAC containing class I is labeled in green with Alexa 488; BAC containing class II is labeled in red with Alexa 568; and BAC containing class III is labeled in yellow with Alexa 633. DNA was counterstained with DAPI. Bar scale: $10 \mu \mathrm{m}$. c-d Radial distribution of MHC genes in resting porcine (c) and human (d) macrophages. Cumulative frequency graphs of the radial position for each MHC class: SLA-1 and HLA-A for class I in green; SLA-DRA and HLA-DRA for class II in red; and TNFa for class III in blue. The cumulative frequency curve of a random distribution $(P(X<d)=d 3$ for $0<d<1$ where $X$ is the random radial position) is shown in black in each graph for comparison. Pairwise comparisons ( $p$-values) of cumulative radial distribution (Student's t-test) are indicated in each graph. The center of the nucleus corresponds to 0 on the $\mathrm{X}$-axis and the periphery to 1

almost twice as small. Similarly, angles A and B are equal, and angle $C$ is three times smaller. In humans, the situation is quite different. It is indeed the $\mathrm{b}$ distances that are about two times smaller than the a and c distances. Concerning the angles, $\mathrm{A}$ and $\mathrm{B}$ are not equal and angle $B$ is the smallest of the three angles. These results add an additional argument for a different 3D organization of the MHC in resting pig and human macrophages (Fig. 3a).
We next investigated whether a response to a pathogen aggression modifies the $3 \mathrm{D}$ organization of the MHC. To answer this question, we carried out the same 3D measurements between the MHC-specific genes in macrophages that have been activated by LPS/IFNY [28]. We compared these measurements in both states (resting and activated). This analysis revealed that the SLA$1 / \mathrm{TNF} \alpha$ distance (c) significantly increases $(p=0.03)$ when the porcine macrophages are activated, suggesting 

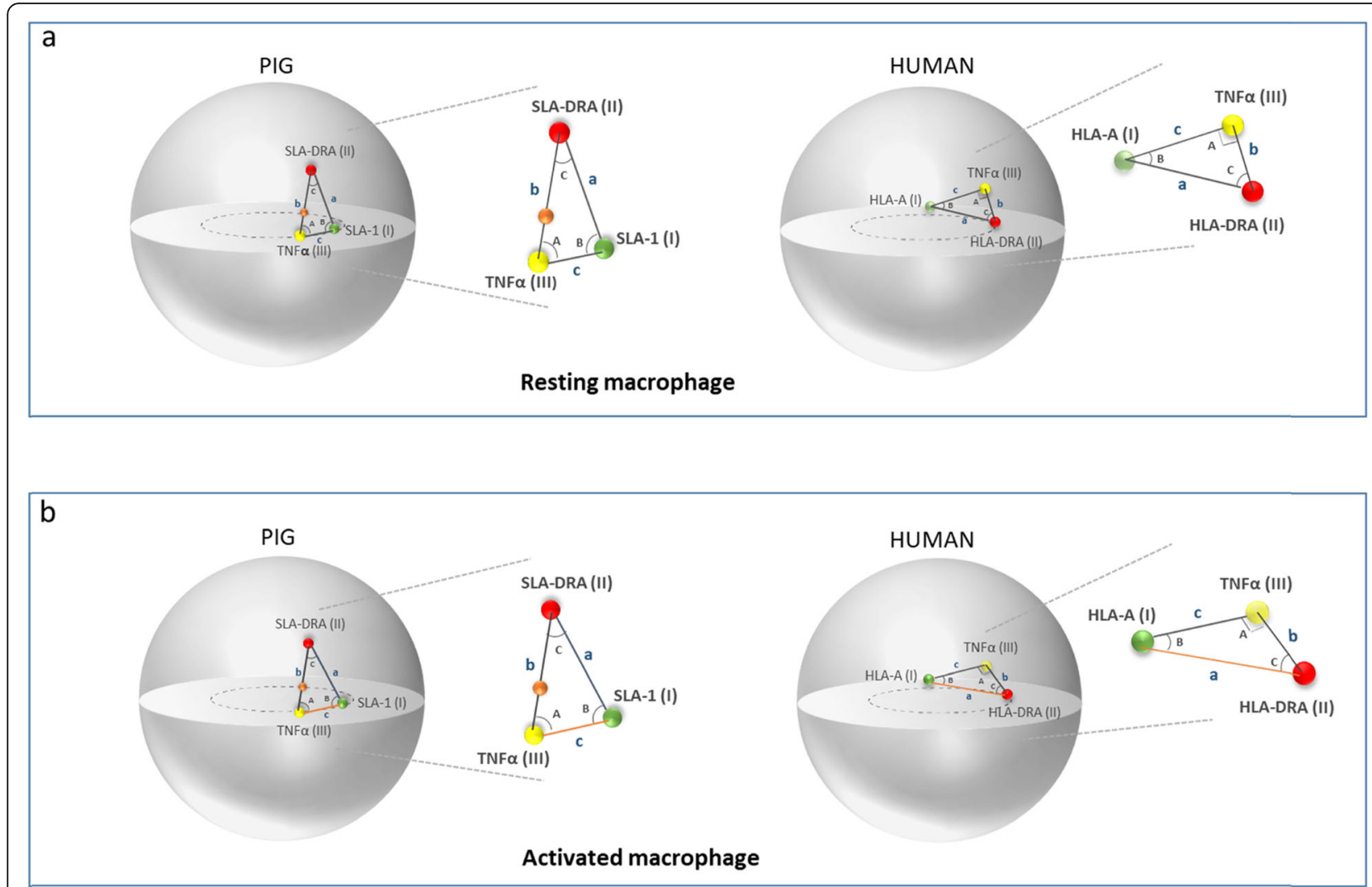

Fig. 3 Schematic representation of the 3D organization of the MHC in resting (a) and LPS/IFNY activated (b) porcine and human macrophages based on the 3D interprobe distance measurements. a: distance class I-class II; b: distance class II-class III; c: distance class I-class III; A: angle class III; B: angle class I; C: angle class II; chromosome 7 centromere: orange point. The 3D distances that increase with macrophage activation are indicated by a red line

a reorganization of the chromatin in this region (Figs. $3 \mathrm{~b}$ and $4 \mathrm{a})$. The distances between SLA-1/SLA-DRA and between TNF $\alpha /$ SLA-DRA do not change (Fig. 4a). Considering the unique feature in the organization of the MHC due to the presence of the centromere separating the class II and class III regions, we completed the analysis by measuring the $3 \mathrm{D}$ center-to-center distances between TNFa and the centromere and between the centromere and SLA-DRA in resting and activated porcine macrophages. The comparison of these measurements in the two states reveals no difference (Additional file 3: Fig. S2). In human macrophages, only one distance significantly increases when the macrophages are activated, but this is the HLA-A/HLA-DRA distance (a) $(p=0.02)$ (Figs. $3 \mathrm{~b}$ and $4 \mathrm{~b})$, reinforcing the hypothesis of a different organization of the complex and chromatin conformation changes due to LPS/IFN $\gamma$ activation in humans and pigs.

\section{Gene expression analysis for the MHC-specific genes}

In order to assess whether the modifications of the 3D organization during the activation process are associated with a change in gene expression, we extracted total
RNA from resting and activated macrophages for both species. We quantified gene expression level by real-time PCR for the genes selected in the MHC. These are SLA1 and HLA-A for MHC class I, SLA-DRA and HLADRA for class II, and TNF $\alpha$ for class III, both in pigs and humans. For MHC classical class I genes, due to the very high sequence homology between SLA-1, SLA-2 and SLA-3 in pigs and, similarly, for their functional orthologs HLA-A, HLA-B and HLA-C [30], it is the cumulative expression of these genes that was assessed. In porcine and human resting macrophages, SLA-1/2/3/ HLA-A/B/C, respectively, and SLA-DRA/HLA-DRA, respectively, are expressed at the same level, which is two to three times the expression level of TNF $\alpha(p=0.003$ and $p=10^{-7}$, respectively) (Additional file 4: Table S2; Fig. 5). When the macrophages are activated by LPS/ IFN $\gamma$, we observed a highly significant over-expression of TNF $\alpha$ both in pigs $(p=0.0001)$ and in humans $(p=$ $\left.4.310^{-6}\right)$. However, we observed a large variability in the expression level of TNFa in pigs, while it is not the case in humans. No significant change in expression level was observed for SLA-1/2/3 and SLA-DRA after macrophage activation, whereas a slight but significant 


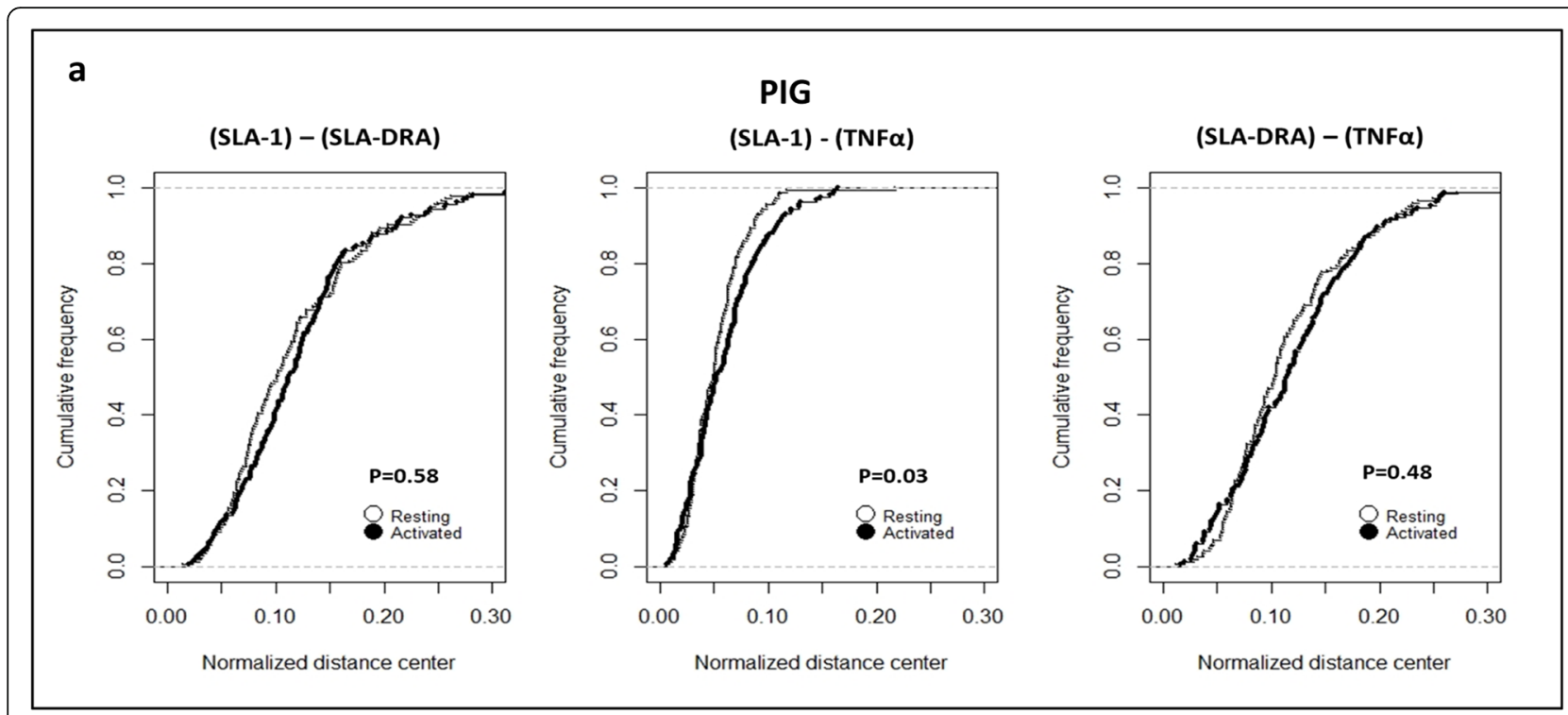

b

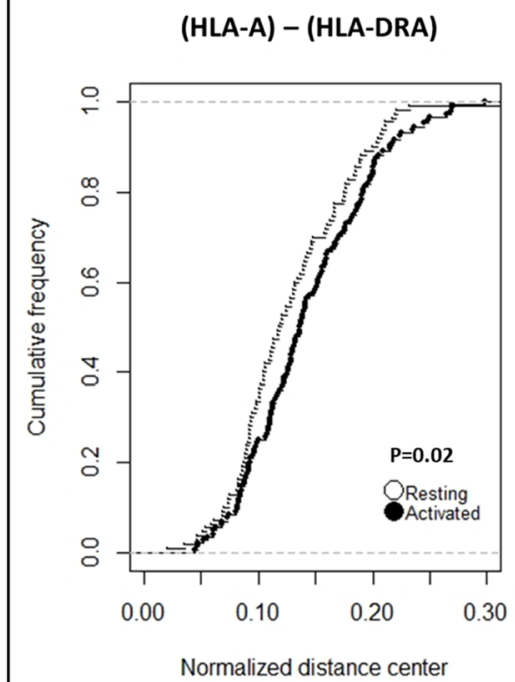

HUMAN

(HLA-A) - (TNF $\alpha)$

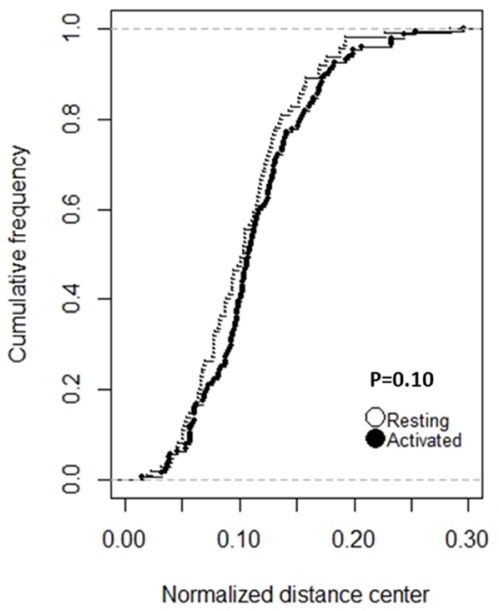

(HLA-DRA) - (TNF $\alpha)$

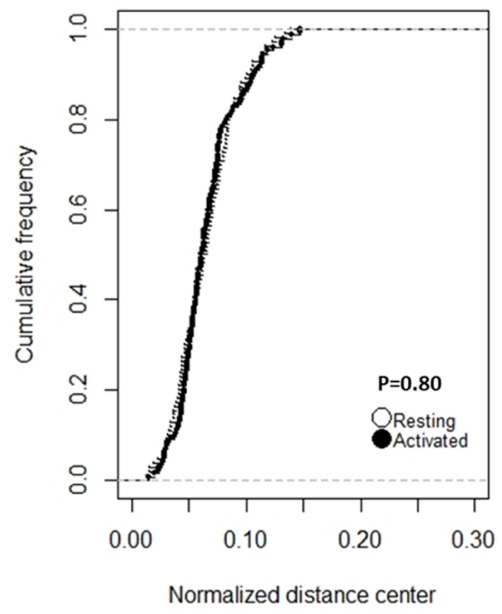

Fig. 4 a-b Analysis of LPS/IFNy activation effects on MHC gene-to-gene 3D distances in porcine and human macrophages. Cumulative frequency graphs of the normalized center-to-center distances between MHC: (i) class I-class II [(SLA-1)-(SLA-DRA); (HLA-A)-(HLA-DRA); (ii) class II-class III [(SLA-DRA)-TNFa; (HLA-DRA)-TNFa]; and (iii) class II-class III [(SLA-1)-TNFa; (HLA-A)-TNFa]. Pairwise comparisons (p-values) of cumulative 3D distance distributions in resting and activated macrophages (Student's t-test) are indicated in each graph

increase in expression was observed for HLA-A/B/C $(p=0.013)$ and HLA-DRA $(p=0.005)$ (Fig. 5). It can therefore be observed that when porcine macrophages are activated, the decompaction of the class I-class III region is accompanied by a strong overexpression of TNF $\alpha$ (class III), whereas in human macrophages, the overexpression of TNF $\alpha$ does not induce the same effect on this distance. In these species, it is the class I-class II region that decompacts in connection with an overexpression of HLA-A/B/C and HLA-DRA. These results provide new elements to reinforce the hypothesis of a different 3D organization and behavior of the MHC in pigs and in humans.

\section{Comparative analysis of the conformation state of the MHC alleles in each nucleus}

We compared the conformation of the two alleles of the same nucleus by performing a single nucleus analysis. Only nuclei in which the two alleles can be clearly differentiated were taken into account. Each allele is defined 

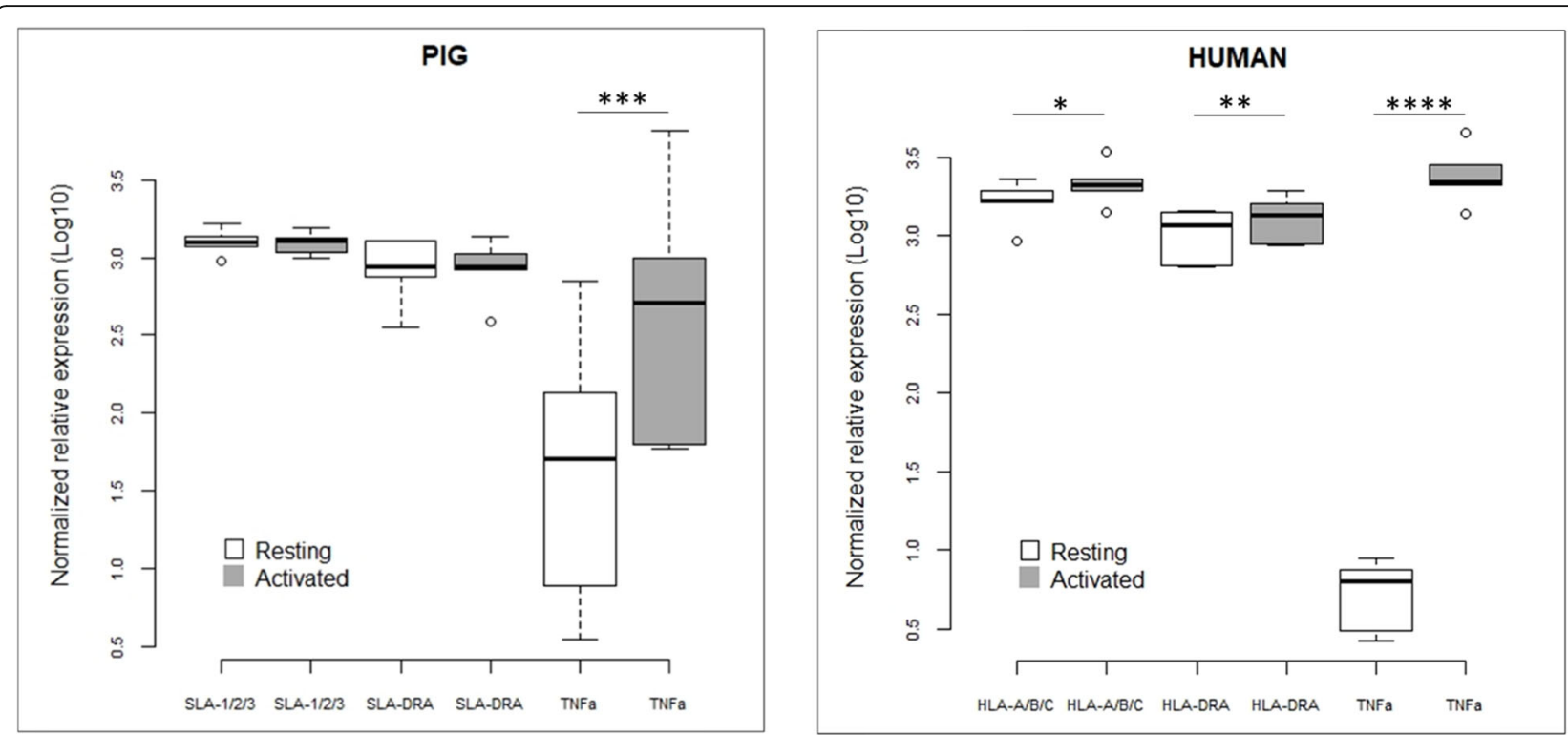

Fig. 5 Normalized relative expression graphs in porcine and human macrophages. mRNA expression level, analyzed by RT-qPCR both in resting and activated macrophages, were pairwise compared with one-way ANOVA models with repetitions. $P$-value class: ${ }^{*} p<0.05$; ${ }^{* *} p<0.01$; ${ }^{* * *} p<0.001,{ }^{* * *} p<10^{-4}$

by three FISH signals for MHC class I, II and III-specific regions, which appear as a compact chromatin cluster (C) or a decompacted chromatin region (D). We first aimed to analyze if the two alleles in each nucleus had the same chromatin compaction state, and then, if the activation of the macrophages induced 3D conformational changes. To address this question, we defined three nucleus patterns using the 3D measurements between the MHC probes (see Methods; Additional file 5: Fig. S3): (i) C-C pattern in which both alleles have a compact cluster conformation; (ii) D-D pattern in which both alleles have a decompacted conformation; and (iii) C-D pattern that represents a mix of the C-C and D-D patterns. Figure 6a illustrates these three patterns. First, to determine whether the two alleles per nucleus have the same conformation in the resting state, we compared the percentage of nuclei harboring the $\mathrm{C}-\mathrm{D}$ pattern to the one with C-C and D-D patterns under the hypothesis that an allele is as likely to be in the compacted state as in the decompacted one. Consequently, the theoretical value for two alleles of a nucleus to be in the C-D conformation is $50 \%$, while it is $25 \%$ for a C-C or D-D conformation. Consequently, the theoretical value for the two alleles to both be in a different (C-D) or similar (C-C or/and D-D) conformation is $50 \%$. In porcine macrophages, we did not observe a difference with an equivalent percentage of nuclei in which the two alleles of the same nucleus have a different conformation (53\% of $C$-D nuclei) and those in which they have the same conformation (47\% of (C-C and D-D) nuclei) (Chi squared test for given probabilities, $p$-value $=0.59$ ).
Similarly, we observed no significant difference in human macrophages since the two alleles of the same nucleus harbor a different conformation in $37.5 \%$ of the nucleus (C-D pattern) and the same conformation in $62.5 \%$ of the nucleus (C-C and D-D pattern) ( $p$-value $=$ $0.08)$. It should be noted that when they harbor the same conformation, it is generally a decompacted one. To analyze the effect of LPS/IFN $\gamma$ activation on these conformations, we then compared the number of nuclei harboring a C-C, D-D or C-D pattern in resting and activated states. The results demonstrate that when porcine macrophages are activated, the number of nuclei with a condensed pattern $(\mathrm{C}-\mathrm{C})$ decreases, while the number of nuclei with a D-D pattern significantly increases $(p$-value $=0.001)$ (Additional file 6: Table S3; Fig. 6b). The same tendency is observed in human cells $(p$-value $=0.048) \quad($ Additional file 6: Table S3; Fig. 6c). These results show an increase in decompaction of the MHC region and are consistent with our measurements of the 3D distances between the selected genes.

\section{Modeling the most probable 3D conformation of the MHC in macrophages and analysis of the impact of cell activation}

To support our experimental observations and take the organization of the complex as a whole into account by extending the analysis of the 3D distances two-by-two, we applied an optimized version of the three-loci algorithm [31]. The goal of this method is to determine the MHC conformation from the relative positions of three loci measured in pig and human macrophages following 
a
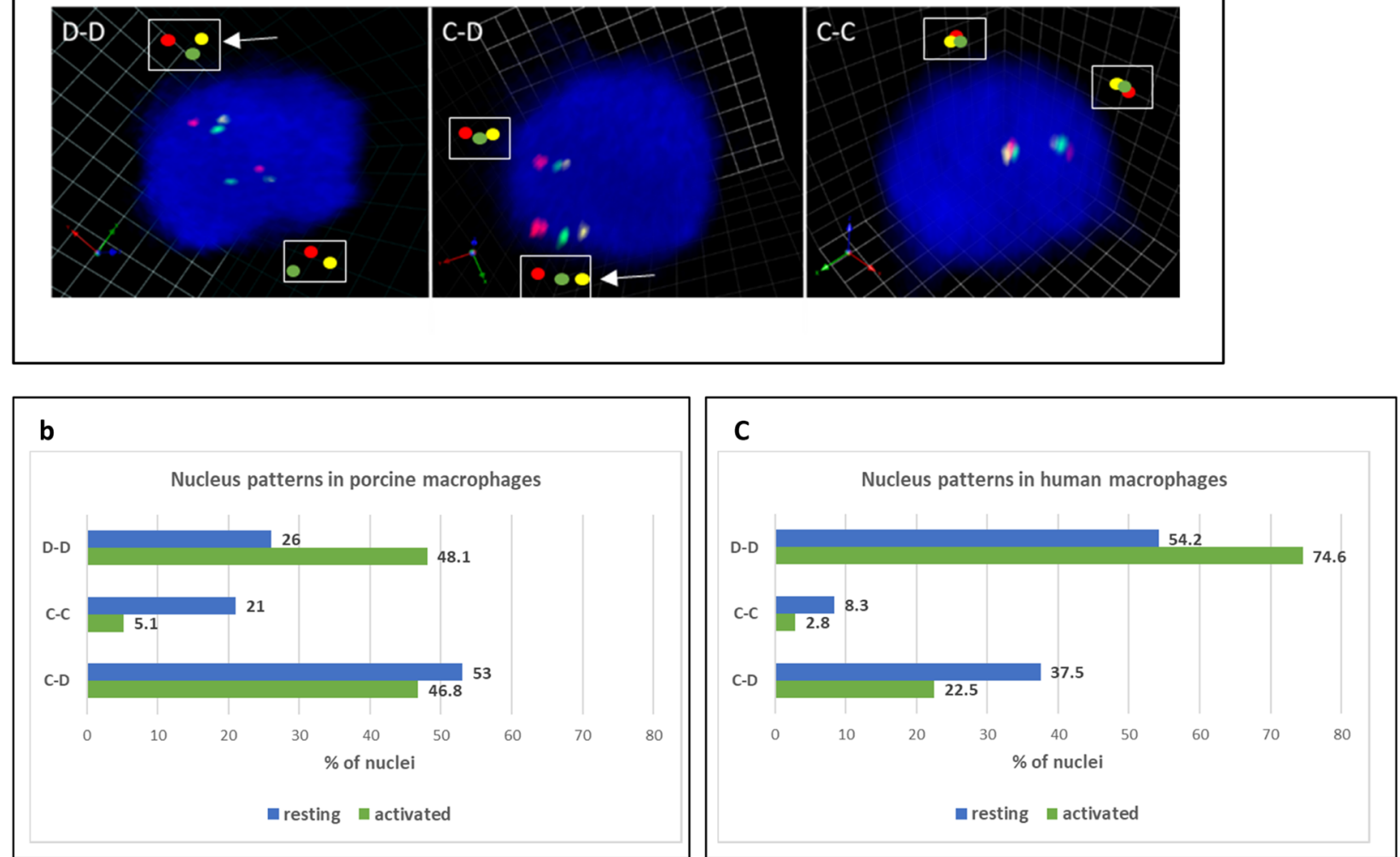

Fig. 6 Single nucleus analysis of MHC allele conformations by 3D-FISH; each allele is defined by three fluorescent spots from BAC containing class I labeled in green with Alexa 488; BAC containing class II in red with Alexa 568; and BAC containing class III in yellow with Alexa 633. a 3D images displaying examples of the three types of nucleus patterns were shown from the captured images obtained with VOLOCITY software. $\mathbf{b}-\mathbf{c}$ Analysis of LPS/IFNy activation effects on the allele conformations. Bar graphs represent the percentage of cells in each pattern

3D FISH experiments. In each nucleus, we observed distinct states of the chromatin fiber, and using the mathematical algorithm, we can assess a physical constraint between three loci within the same chromosome segment. The mathematical model is based on the assumption that each labeled locus moves in a specific area called a survival zone (SZ). Thus, we can determine the survival zones of each gene SZ $\mathrm{SLA-1(HLA-A)}, \mathrm{SZ}_{\mathrm{TNF} \alpha}$ and $\mathrm{SZ}_{\text {SLA-DRA }}$ (HLA-DRA) within a single cell in pigs and humans, respectively (Additional file 7: Fig. S4; Fig. 7). While class III SZ (SZ TNF $\alpha$ ) is similar in resting porcine and human cells $(R=0.44$ and $R=0.43$, respectively), the SZ of the two other classes (SZ SLA-1(HLA-A) and $\mathrm{SZ}_{\text {SLA-DRA }}$ (HLA-DRA) show notable differences between pigs and humans. Indeed, the class II region is markedly more constrained in humans than in pigs, whereas the opposite is observed for class I, which is more constrained in pigs. All this reinforces the hypothesis of a different 3D organization of SLA and HLA complexes in resting cells. When the macrophages are activated, there is an overall decrease in the space occupied by the MHC in both species. However, some differences are noteworthy. In porcine cells, the SZ DRA is reduced from $R=0.166$ to $R=0.129$, but the most striking feature concerns SLA-1. The size of its SZ is considerably reduced (from $R=0.063$ to $R=0.019$ ) and its position changes substantially with a tendency to move towards SLA-DRA (Fig. 7). Globally, these observations reflect that the freedom of motion of the loci is reduced upon activation. The reduction of the SZs is consistent with the finding that the area explored by actively transcribed loci is confined upon transcription activation [32]. In human macrophages, we observed little change when the cells are activated except for the $\mathrm{SZ}$ of HLA-A, which is reduced from $R=0.156$ to $R=0.096$. Since the MHC is located on the same chromosomal arm, gene activation may require less effort to fold this domain upon LPS/IFN $\gamma$ activation.

\section{Discussion}

In this study, we analyzed the 3D conformation of MHC in macrophages, one of the most gene-dense genomic regions in mammals. Due to its key function in immunity, this complex has been widely investigated in terms 


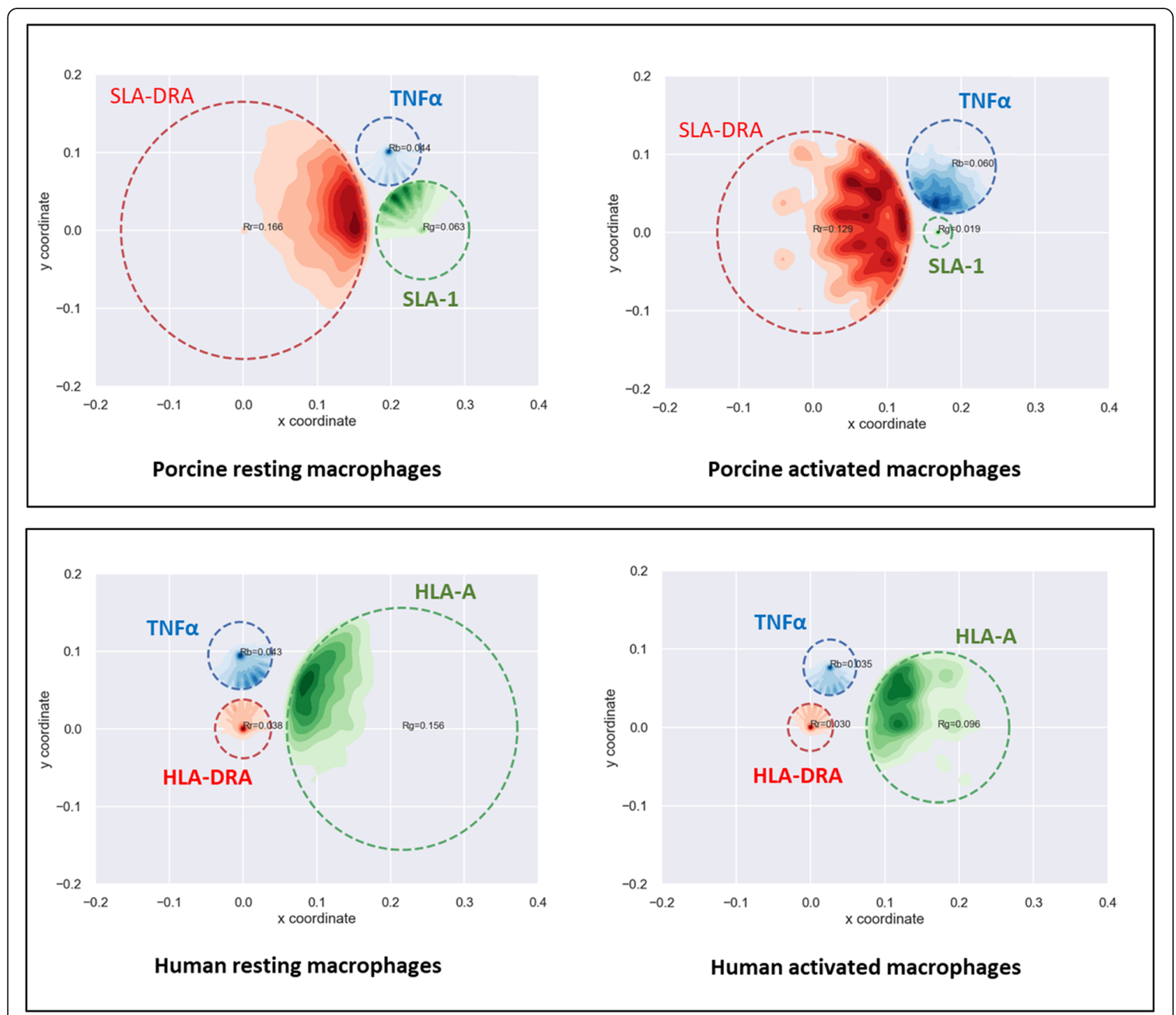

Fig. 7 Modeling the relative positions or survival zones $(\mathrm{SZs})$ in resting and activated macrophages of three loci of the MHC whose positions are spatially linked. The loci are SLA-1/HLA-A (class I) in green, TNFa (class III) in blue, and SLA-DRA/HLA-DRA in red. The mathematical approach makes it possible to determine the specific area (SZ) in which each locus moves in resting and activated macrophage nuclei. These SZ are represented by colored dotted circles. The radii $\left(R_{g}, R_{b}\right.$ and $\left.R_{r}\right)$ of the SZs are indicated for each locus. All the different locus positions $(X, Y)$ are reconstructed inside survival zones. The Python module, Seaborn, is used for 2D kernel density estimation of reconstructed points (https://seaborn.pydata.org/index.html)

of sequence, genetic diversity, gene function and expression, both in humans [6] and in pigs [8]. However, few studies have reported on its 3D organization in the nucleus of immune cells like macrophages, even though the important role of this organization on the regulation of gene expression has been widely demonstrated in many cell types $[13,33]$.

\section{Intermediate radial positioning of a gene-dense region}

To investigate how the consecutive genes that compose the MHC are spatially arranged in interphase nuclei, we selected BACs containing genes representative of each
MHC region in human and in pig macrophages to first analyze their radial position and then their gene-to-gene distances. We found that MHC class I, class II and class III regions had a non-random spatial organization in both species (Fig. 2). We showed that these three genes are at the same radial position in porcine macrophages, probably located in an intermediate position rather than inside or on the periphery of the nucleus. The same situation is observed in human macrophages for genes in class II and class III with an intermediate radial position, whereas the class I gene (HLA-A) harbors a significantly different position, with a clear tendency to be more 
toward the periphery. Considering that these genes are located in a gene-dense genomic region and are expressed in resting macrophages, a more central position in the nucleus would have been expected. Indeed, a neighborhood effect has been suggested by the observation that radial positioning often correlates with local gene density, with locally gene-dense regions preferentially having an internal position. This was first shown at the whole chromosome level with gene-poor chromosomes positioned toward the nuclear periphery and gene-rich chromosomes inside the nucleus [34], and then at the single gene level [35]. In addition, several studies have suggested that a functional link exists between gene activity and radial positioning, where active genes are preferentially located inside the nucleus (reviewed in [36]). However, this is not a universal hallmark. While some authors have demonstrated that locations closer to the nuclear periphery are not incompatible with active transcription [37, 38], others have even suggested that there is not necessarily a correlation between gene activity level and radial positioning [39]. We also previously demonstrated in porcine macrophages that there is not always a link between radial positioning and variations of expression since downregulated genes can occupy the same radial position as up-regulated genes [28]. The data presented in this study are consistent with this hypothesis considering the radial positioning of the three MHC genes analyzed and their level of expression in resting macrophages in both species.

Different 3D organization of the MHC in humans and pigs The 3D gene-to-gene distance measurements allowed us to demonstrate that the MHC class I, class II and class III genes have a non-linear organization in the nuclei of macrophages. Indeed, in porcine macrophages, our results indicated that SLA-DRA tends to be at an equivalent distance of SLA-1 and TNF $\alpha$ (Fig. 3a; Additional file 2: Table S1) in contrast to the genomic map where it is at a physical distance of $1.9 \mathrm{Mb}$ and $1.1 \mathrm{Mb}$ from SLA-1 and TNFo, respectively (Fig. 1). On the contrary, in human macrophages, there is a good correlation between the distances in megabases and the 3D measured distances (Fig. 1; Additional file 2: Table S1). The mean values of the internal angles were calculated using all 3D distance measurements. This allowed us to propose a different 3D conformation for the MHC in porcine and human macrophages (Fig. 3a).

We then investigated whether the activation process modifies these conformations. Our results demonstrate that upon LPS/IFN $\gamma$ activation, a decompaction of the chromatin is observed in the HLA and SLA complexes but it does not affect the same regions. In fact, it is the class I (HLA-A)-class II (HLA-DRA) distance that significantly increases in human activated macrophages, whereas it is the class I (SLA-1)-class III (TNF $\alpha$ ) distance in the porcine cells (Fig. 4a-b). The differences we observed both in the 3D conformation of the human and porcine $\mathrm{MHC}$ and in the effects following macrophage activation are not surprising when all the elements of comparison between the human and porcine $\mathrm{MHC}$ are accounted for. Considering human and swine $\mathrm{MHC}$, there is a high overall level of conserved synteny. These two genomic regions are delimited by MOG upstream from the class I region and RING1 downstream from the class II region [8]. The anchor genes that delimit the three regions are found in both species: (i) MOG and MCCD1 for class I; (ii) MCCD1 and BTNL6 for class III; and (iii) BTLN2 and RING1 for class II. However, there are several points in which SLA and HLA complexes significantly differ [40]. The first one concerns the size and organization of the class I region. It is organized into two clusters and spans $1.06 \mathrm{Mb}$ in swine, whereas it is organized into three clusters and spans $1.89 \mathrm{Mb}$ in humans. This difference in size corresponds to a segment of $300 \mathrm{~kb}$ present in the HLA and absent in the SLA complex [10]. The second important difference has to do with the position of the centromere. The porcine MHC is unique in that the class II region is separated from the class III and class I regions by the centromere. This could imply major differences in the 3D organization of the human and porcine MHC. The importance of centromeres in the genome 3D organization has only just begun to be recognized [41]. It has, at least in part, probably to do with the nature of their sequences. Centromeres are associated with large arrays of tandemly alpha satellite DNA sequences flanked on both sides by compact blocks of constitutive heterochromatin. An example of their strong topological impact has been reported through $\mathrm{Hi}-\mathrm{C}$ data that have demonstrated that centromeres could act as a barrier to intrachromosomal arm interactions [41]. The pericentromeric heterochromatin would also have a preventive role, hindering the invasion of the centromeric region in euchromatin [42]. The conformational changes we observed in activated compared to resting porcine macrophages by applying the three-loci algorithm could indicate that chromatin reorganization within the porcine MHC is greater due to the physical barrier caused by the centromere.

\section{Conformation of MHC alleles in the same nucleus}

It has been shown that because genome organization is inherently flexible, the two alleles in a cell may be differentially organized at the chromatin architecture level. The most striking examples are often associated with cellular processes that require persistent differences in allele function, such as dosage compensation, imprinted 
genes, and monoallelically expressed genes [21]. However, using high-throughput methods (genome-wide Hi$\mathrm{C}$ and large imaging datasets) to study genomic interactions in the nucleus, the authors have extended these specific examples and have highlighted the high level of heterogeneity in spatial genome organization among individual cells as well as between alleles in the same cell [21]. Using the 3D distance measurements between the MHC target genes, we defined a conformation state for each allele. Even if we do not have allele-specific probes, it was possible to compare the conformation of the two alleles of the same nucleus by performing a single nucleus analysis. This also allowed us to pinpoint a heterogeneity in chromatin conformation between alleles in the same nucleus, both in porcine and human resting macrophages, with as many nuclei in which the two alleles have a different conformation as nuclei in which they have the same conformation. This variability in allele conformation could be linked to their expression status. Indeed, it has been demonstrated, by investigating single-cell transcriptome, that active transcription generally occurs in bursts ranging from minutes to hours in length. Given its inherent stochastic nature, transcriptional bursting is not coordinated between homologous alleles. Thus, at any given point in time, only one allele may be actively transcribing for a given gene [43-45]. This pattern of punctuated gene transcription has been observed even for genes with very high levels of expression. The chromatin in the vicinity of actively expressed genes are less condensed and in a more open state than in the vicinity of non-expressed genes. This is to facilitate the access of the transcription machinery to chromatin.

When macrophages are activated by LPS/IFN $\gamma$, we observe a very significant increase in the number of alleles, showing a decompacted conformation both in humans and in pigs. This is associated with the up-regulation of the three MHC target genes in human macrophages and with the up-regulation of TNF $\alpha$ in porcine cells. These results are in agreement with those we previously obtained. We in fact demonstrated that when macrophages are LPS/IFN $\gamma$ activated, several cytokines, including TNF $\alpha$, have a tendency to be outside their chromosome territories [28], suggesting that the transcriptional activation leads to decompaction or the disturbance of chromatin loops to facilitate transcription. Several studies focusing on the MHC have also already demonstrated such a phenomenon after up-regulation by IFN $\gamma$ in cell types other than immune cells, including fibroblasts and fibrosarcoma-type cancer cells $[24,46,47]$. They reported that chromatin carrying the entire MHC undergoes massive higher-order remodeling mediated by the transcription factor STAT1. However, they made the assumption that external loops might not be an absolute requirement for transcription per se since even within a population of cells that is expressing the locus at a very high level, the MHC was found on an external loop in a maximum of $35 \%$ of the chromosome territories [46]. Our study suggests that in immune cells, this phenomenon of MHC chromatin remodeling upon LPS/IFN $\gamma$ activation is probably more widespread since we observed a high percentage of MHC alleles in a decondensation state both in human and in porcine macrophages. This phenomenon is probably related to their function in the immune response since they are the first actors in the inflammatory process.

In further research, it would be interesting to extend this single-cell approach that revealed a higher percentage of decondensed MHC alleles in activated macrophages by performing DNAse1 hypersensibility assay which allows targeting the regions of chromatin that have lost their compact structure. This kind of approach has been performed to map the DNAse 1 hypersensitive regions in the $\mathrm{MHC}$ of Primates to determine the disease-causing variants for most major histocompatibility complex (MHC)-associated diseases [48]. Similarly, as we detected a strong overexpression of TNF $\alpha$ in human and porcine macrophages following LPS/IFN $\gamma$ activation, a comparative study of its epigenetic profile [49] (both at the DNA methylation and histone marks levels) in resting and activated cells would further our results.

\section{Conclusion}

This study adds new data on the 3D organization in macrophage nuclei of one of the most important regions of the genome since its contains the MHC, which plays a crucial role in the immune response. We showed that this complex adopts a different 3D conformation in porcine and in human macrophages. The activation of the cells by LPS/IFN $\gamma$ modifies this organization more noticeably in porcine cells. The presence of the centromere within the SLA complex, which is a particularity in pigs, could be a factor that could explain, at least in part, the observed differences.

\section{Methods}

\section{Ethics statement}

Our experiment was conducted in accordance with the French national regulations for human care and use of animals in research. Swine blood samples were collected on Large White pigs from UMR INRAE Toxalim under the experimentation agreement number TOXCOM/ 0020/PP AL. Human blood samples from healthy donors were provided by Etablissement Français du sang (Toulouse, France). 


\section{Cell preparation and activation}

Porcine monocytes were isolated as previously described [28] with few modifications. Briefly, peripheral blood mononuclear cells (PBMCs) were separated by density gradient centrifugation $(1.077 \mathrm{~g} / \mathrm{l}$, Lymphoprep, Eurobio,les Ulis, France) for $30 \mathrm{~min}$ at $800 \mathrm{~g}$ at room temperature. PBMCs were collected and submitted to a lysis solution $\left(\mathrm{NH}_{4} \mathrm{Cl} \quad 0.15 \mathrm{M} \quad \mathrm{KHCO}_{3} 0.01 \mathrm{M}\right.$-EDTA $\left.\mathrm{Na}_{2} \quad 1 \mu \mathrm{M}\right)$ for $5 \mathrm{~min}$ to eliminate red cells. One- $\times 10^{8}$ cells were distributed on CellBIND ${ }^{\circ}$ flask in RPMI-1640 supplemented with penicillin-streptomycin $(100 \mathrm{U} / \mathrm{ml})$ and without FCS to allow for their adherence. After $4 \mathrm{~h}$ at $37^{\circ} \mathrm{C}$ in humidified atmosphere $5 \% \mathrm{CO}_{2}$, medium was replaced by RPMI-1640 supplemented with 10\% FCS, $1 \%$ non-essential amino acids (Sigma-Aldrich, Saint Quentin Fallavier, France) and 10\% of CSF-1 growth factor (LADMAC cell medium, [50]) for the generation of monocyte-derived macrophages. Flasks were placed at $37{ }^{\circ} \mathrm{C} 5 \% \mathrm{CO}_{2}$ for 4 days. The cells were then submitted to labelling with antihuman CD14 antibody (MACS CD14 microbeads, Miltenyi Biotec, Paris, France). The CD14+ cells were selected with an AutoMACS separation column (Miltenyi Biotec) according to the manufacturer's instructions. Macrophages were suspended in RPMI-1640 to a final concentration of $5.10^{6}$ cells $/ \mathrm{ml}$.

Human CD14+ monocytes were isolated from blood as previously described [51]. They were then distributed on glass coverslips at $1-1.5 \times 10^{6}$ cells in 6 -well plates in RPMI 1640 without FCS to allow for their adherence. After $2 \mathrm{~h}$ at $37 \mathrm{C}$ in humidified $5 \% \mathrm{CO}_{2}$ atmosphere, the medium was replaced by RPMI 1640 containing 10\% heat-inactivated FCS, antibiotics and $20 \mathrm{ng} / \mathrm{ml} \mathrm{M-CSF}$ (PeproTech, Rock Hill, NJ, USA). They were maintained in culture for 6-8 days to differentiate into macrophages.

Human and porcine macrophage samples were divided in two: one part was incubated in culture medium (resting batch), the other in a culture medium supplemented with LPS $(10 \mu \mathrm{g} / \mathrm{ml})$ and IFN $\gamma(1 \mathrm{ng} / \mathrm{ml}$, activated batch) for $3 \mathrm{~h}$ at $37^{\circ} \mathrm{C}$ according to the activation conditions defined previously [28].

\section{D-FISH experiments}

\section{Slides for 3D-FISH}

A suspension of $5 \times 10^{6}$ cells $/ \mathrm{ml}$ of porcine macrophages in RPMI 1640 was applied to poly-L-lysine slides for 10 min for cell adhesion. 3D fixation was performed at room temperature for $10 \mathrm{~min}$ in $4 \%$ paraformaldehyde freshly made followed by a short wash in PBS. Slides were then immersed in $20 \%$ glycerol solution for $30 \mathrm{~min}$ and stored at $-80^{\circ} \mathrm{C}$.

Glass-coverslips with spread human macrophages were placed $10 \mathrm{~min}$ in $4 \%$ paraformaldehyde followed by a short wash in PBS and used immediately for 3D FISH without freezing.

\section{DNA probes}

The porcine BAC clones containing MHC class I (SLA1, SBAB-490B10) [52], class II (SLA-DRA, SBAB-591C4) and class III (TNF $\alpha$, SBAB-493A6) genes [10] and the one labelling the SSC7 centromere (SBAB-437A9) were isolated from a swine BAC library [53] (CRB-Anim, INRA, 2018. Biological Resource Centres for domestic animals of AgroBRC, doi: https://doi.org/10.15454/1. 5613785622827378E12). The human BAC clones containing orthologous genes were purchased from BACPAC Resources at Children's Hospital and Research Center [54] (RPCI human BAC library 11, Oakland, USA: https://bacpacresources.org;): MHC class I (HLAA, RP11-192H11), class II (HLA-DRA, RP11-379F19), class III (TNF $\alpha$, RP11-184F16). The presence of the selected genes in each BAC clone was verified by PCR using the primers listed in Table 1. Approximatively 50 ng of BAC DNAs were random priming labelled using the Bioprime DNA labeling kit (Invitrogen, CergyPontoise, France). For multiple-label experiments, BAC containing class I and BAC containing class II were directly labelled by incorporation of dUTP Alexa 488 and dUTP Alexa 568 (Invitrogen) respectively. The BAC containing TNF $\alpha$ (class III region) and the BAC specific for SSC7 centromere were labelled with biotinylated dUTP (Roche) revealed with streptavidine-Alexa-633 (Invitrogen). The same procedure is applied to porcine and human BAC probes. Products from the labelling reaction of the three BACs in each species were pooled and precipitated with porcine or human Cot-1 DNA (Applied Genetics Laboratories, Melbourne, USA) and salmon sperm DNA (Eurobio, Les Ulis, France). Probes were dropped onto macrophage slides or coverslips at a final concentration of $100 \mathrm{ng} / \mu \mathrm{l}$ in a hybridization buffer. The specificity of the probes was previously tested by 2D-FISH on porcine or human metaphase spreads (Additional file 1: Fig. S1) prepared from lymphocytes according to protocols, which had previously been described [55].

\section{$3 D$ FISH experiment}

3D FISH experiments were carried out as previously described [28] both for porcine and human macrophages. Briefly, slides were successively immersed in $0.5 \%$ Triton $\mathrm{X}-100-$ Saponin solution and Tris- $\mathrm{HCl}$ 0.1 M pH 7.2. Cells were then freeze-thawed six times in liquid nitrogen, treated with $200 \mu \mathrm{g} / \mathrm{ml}$ RNase and $0.1 \mathrm{~N} \mathrm{HCl}$ solution. Finally, slides were incubated in 2XSSC-50\% formamide for at least 3 days at $4{ }^{\circ} \mathrm{C}$. Cells and probes were simultaneous denatured $5 \mathrm{~min}$ at $72{ }^{\circ} \mathrm{C}$ and incubated $72 \mathrm{~h}$ at $37^{\circ} \mathrm{C}$ in a DAKO hybridizer. Posthybridization washes were performed twice in $2 \mathrm{X}$ SSC at room temperature for $15 \mathrm{~min}$, then three times for 15 min in 2X SSC, $50 \%$ formamide $\mathrm{pH} 7.0$ at $45^{\circ} \mathrm{C}$ and 
finally, three times for $15 \mathrm{~min}$ in $0.1 \mathrm{X} \mathrm{SSC}$ at $45^{\circ} \mathrm{C}$. Nuclei were counterstained with 4',6'diamidino-2-phenylindole in Vectashield medium (Vector Laboratories, Burlingame, USA).

\section{Confocal microscopy and image analyses}

Confocal microscopy was carried out using a Leica TCS SP2 confocal microscope (Leica Instruments, Heidelberg Germany) equipped with an oil immersion objective (plan achromatic $63 \times$ N.A. $=1.4$ ). The Z-stacks were acquired at $1024 \times 1024$ pixels per frame using an 8-bit pixel depth for each channel at a constant voxel size of $0.079 \times 0.079 \times 0.244 \mu \mathrm{m}$. Typically, a stack of 45 confocal planes was acquired. Segmentations and 3D measurements between objects were done using NEMO software [29]. The radial position of the genes was calculated using the distance between the gene center and the nucleus center normalized by the nucleus local radius. The 3D gene center-to-gene center distances were normalized by the nucleus local diameter for each scored cell. To compare the conformation of the two alleles in each nucleus, we defined three nucleus patterns: (i) D-D pattern (Decompacted) when the three loci that define each allele were found separed by a distance $d_{1} \geq 2 r$, given that $r$ is the radius of the fluorescent spot that represents the loci, (ii) C-C pattern (Compacted) when the three loci that define each allele were found separed by a distance $\mathrm{d}_{2} \leq 2 \mathrm{r}$ and (iii) C-D pattern when the three loci that define one allele were found separed by a distance $\mathrm{d}_{2} \leq 2 \mathrm{r}(\mathrm{C})$ while the distances between the three loci that define the other allele were $d_{1} \geq 2 r$ (D) (Additional file 5: Fig. S3).

\section{Quantitative real time RT-PCR}

The primers for quantitative real time $\mathrm{PCR}$ are those used for the control of the BAC specificity as they have been chosen in exons (Table 1). The $\beta$-2-Microglobulin was chosen as the internal reference gene. Resting and activated macrophage samples of 5 pig and 5 human donors were used. Total RNA was isolated with NucleoSpin $^{\circ}$ RNA kit (Macherey Nagel) according to the manufacturer instruction. The integrity and quantification of the RNA samples were assessed using an Agilent Bioanalyzer 2100 with a RNA 6000 Nano Lab. RNA $(0.5 \mu \mathrm{g})$ with a RIN score between 8 and 10 were reverse transcribed using random primers and Superscript III enzyme (Life Technologies). The resulting cDNA samples were diluted $1 / 25$. QPCR was performed in duplicate with $2 \mu \mathrm{l}$ of the dilution in a final volume of $8 \mu \mathrm{l}$ using SYBR $^{\text {ti }}$ Green PCR Master Mix (Applied biosystems) on a QuantStudio6 real-time PCR System (Thermo Fisher Scientific) as previously described [56]. The efficiency of real-time PCR amplification was calculated for each primer pair using six serial dilution points from a cDNA pool including pure resting and activated cDNA samples from resting and activated samples (1:5; $1: 10 ; 1: 20 ; 1: 40 ; 1: 80 ; 1: 160)$. After determination of the threshold cycle $(\mathrm{Ct})$ for each sample, the PFAFFL method was applied to calculate the relative expression of each gene [57] using the cDNA pool as calibrator sample.

\section{D modeling of the MHC conformation: inferring survival zone radius}

In our model, we assumed that in the time interval $\Delta t$, the genes move into regions whose confinement radii are $R_{n}, R_{g}$ and $R_{b}$ (Additional file 7: Fig. S4). These regions are called locus survival zones. Indices $r, g$ and $b$ correspond to the loci: $r=S L A-D R A, g=S L A-1, \quad b=$ TNF $\alpha$ for the pig and $r=H L A-D R A, g=H L A-A, \quad b=$ $T N F \alpha$ for the human.

If we denote by $\left((R-G)_{i}\right)_{i=1 .}, n,\left((G-B)_{i}\right)_{i=1 . n}$ and $\left((R-B)_{i}\right)_{i=1 .}, n$ different distances between the loci, we can set.

$$
\begin{aligned}
& d_{\text {rgmin }}=\min \left(\left((R-G)_{i}\right)_{i=1 . . n}\right) d_{\text {rgmax }}=\max \left(\left((R-G)_{i}\right)_{i=1 . . .}\right) \\
& d_{r b \min }=\min \left(\left((R-B)_{i}\right)_{i=1 . . n}\right) d_{r b \max }=\max \left(\left((R-B)_{i}\right)_{i=1 . . n}\right) \\
& d_{\text {gbmin }}=\min \left(\left((G-B)_{i}\right)_{i=1 . . n}\right) d_{g b \max }=\max \left(\left((G-B)_{i}\right)_{i=1 . . n}\right)
\end{aligned}
$$

Where $n$ is the number of cells, $\min ()$ is the minimum function and $\max ()$ is the maximum function.

Survival zones radii can be expressed by the expressions:

$$
\begin{aligned}
R_{g} & =\frac{d_{\text {rgmax }}+d_{\text {gbmax }}+d_{\text {rbmin }}-d_{\text {rbmax }}-d_{\text {rgmin }}-d_{\text {gbmin }}}{4} \\
R_{b} & =\frac{d_{\text {rbmax }}+d_{\text {gbmax }}+d_{\text {rgmin }}-d_{\text {rgmax }}-d_{\text {rbmin }}-d_{\text {gbmin }}}{4} \\
R_{r} & =\frac{d_{\text {rgmax }}+d_{\text {rbmax }}+d_{\text {gbmin }}-d_{\text {gbmax }}-d_{\text {rgmin }}-d_{\text {rbmin }}}{4}
\end{aligned}
$$

\section{Abbreviations}

2D FISH: Two-dimensional fluorescence in situ hybridization; 3D FISH: Threedimensional fluorescence in situ hybridization; BAC: Bacterial Artificial Chromosome; CT: Chromosome Territory; DAPI: 4', 6' diamidino-2phenylindole; SSC: Sus scrofa domestica; MHC: Major Histocompatibility Complex; MOG: Myelin Oligodendrocyte Glycoprotein; RING1: Ring finger protein 1; MCCD1: Mitochondrial Coiled-Coil Domain 1; BTNL2: Butyrophilinlike 2; BTNL6: Butyrophilin-like 6

\section{Supplementary Information}

The online version contains supplementary material available at https://doi. org/10.1186/s12860-021-00384-4.

Additional file 1 Fig. S1. BAC probe specificity control by 2D-FISH on porcine metaphases. (a) class I (SLA-1, SBAB-490B10) in green; class II (SLA-DRA, SBAB-591C4) in red; and class III (TNFa, SBAB-493A6) in yellow. (b) porcine chromosome 7 centromere in red (SBAB-437A9). (c) BAC probe specificity control by 2D-FISH on human metaphases: class I (HLAA, RP11-192H11) in green; class II (HLA-DRA, RP11-379F19) in red; and class III (TNFa, RP11-184F16) in yellow. 
Additional file $\mathbf{2}$ Table S1. Mean values of 3D normalized center-tocenter distances and angles calculated using center-to-center distances.

Additional file $\mathbf{3}$ Fig. S2. 3D BAC center-to-center distances in resting and activated swine macrophages. Cumulative frequency graphs of the normalized center-to-center distances between: (i) MHC class III (TNFa) and SSC7 centromere in red; (ii) MHC class II (SLA-DRA) and SSC7 centromere in green. Pairwise comparisons ( $p$-values) of cumulative 3D distance distributions in resting and activated macrophages (Student's t-test) are indicated in each graph.

Additional file $\mathbf{4}$ Table S2. Comparison of gene expression level in resting macrophages. mRNA expression level, analyzed by RT-qPCR, were pairwise compared with one-way ANOVA model with repetitions.

Additional file 5 Fig. S3. Schematic representation of the method used to define the conformation of each allele: given that $r 1$ and $r 2$ are the radii of two fluorescent spots, when the $3 \mathrm{D}$ distance between two spot centers $(\mathrm{d} 1)$ is greater than $r 1+r 2$, the allele is assumed to be decompacted (D), whereas when the 3D distance $(\mathrm{d} 2)$ between two spot centers is less than $r 1+r 2$, the allele is assumed to be compacted (C).

Additional file $\mathbf{6}$ Table S3. Nucleus-by-nucleus analysis of pairs of allele conformations and of the effects of LPS/IFNY activation.

Additional file $\mathbf{7}$ Fig. S4. Schematic representation of genes positioned inside survival zones (SZ) as determined by the application of the threeloci algorithm. The probable positioning of three genes (blue, red and green dots) is represented in two cells as an example (in cell 1 shown by dotted lines, and in cell 2 by continuous lines). The different positions of each gene make it possible to define its $S Z$ represented by a circle of the same color. The radius of the circle defined for each locus is denoted by $\mathrm{Rb}$ for the blue dot, $\mathrm{Rr}$ for the red dot and $\mathrm{Rg}$ for the green dot.

\section{Acknowledgments}

The authors would like to thank Dr. Philippe Pinton and his co-workers (INRAE ToxAlim unit Toulouse) for providing porcine blood samples. 3D acquisitions were performed at the T.R.I.

Genotoul (Toulouse Réseau Imagerie) imaging core facility in Toulouse (France): http://trigenotoul.com/. We are grateful to Alain Jauneau, Cécile Pouzet and Aurélie Leru for their help and the use of the FR AIB facility for microscopy.

\section{Authors' contributions}

F.M and M.Y-B designed and conceived the study. F. M performed the experiments. A. B supervised the gene expression experiment and associated data analysis. D. R performed the statistical analysis. A. K developed and performed the 3D modeling algorithm. F. M, Y.L-M, C.R-G, S. K and M.B-Y analyzed the data and wrote the manuscript. All authors read and approved the manuscript.

\section{Funding}

This study was funded by the INRAE Animal Genetics Division (France) and the INRAE GenPhySE (Génétique, Physiologie et Systèmes d'Elevage) Laboratory (Toulouse).

\section{Availability of data and materials}

The datasets supporting the conclusions of this article are included within the article, its additional files. All relevant raw data have been deposited at https://doi.org/10.15454/IEWMSH

\section{Declarations}

\section{Ethics approval and consent to participate}

Our experiment was conducted in accordance with the French national regulations for human care and use of animals in research. The study used swine blood samples from animals conducted with the approval of the Ethics committee of Pharmacology-Toxicology of Toulouse-Midi-Pyrénées in animal experimentation (Toxcométhique), TOXCOM/0020/PP IO (Date of approval: 18 January 2013), in accordance with the European Directive on the protection of animals used for scientific purposes (Directive 2010/63/EU). Human blood samples from healthy donors were provided by Etablissement Français du Sang, Toulouse, France under contract EFS-PM:21PLER2015-0010. According to articles L1243-4 and R1243-61 of the French Public Health
Code, the contract was approved by the French Ministry of Science and Technology (agreement number AC 2009-921, Jan 2017).

\section{Consent for publication}

Not applicable.

\section{Competing interests}

The authors declare that they have no competing interests.

\section{Author details}

${ }^{1}$ GenPhySE, Université de Toulouse, INRAE, ENVT, 1388 GenPhySE, 24 Chemin de Borde Rouge, 31326 Cedex Castanet-Tolosan, France. ${ }^{2}$ Laboratoire de Biologie Moléculaire Eucaryote (LBME), Centre de Biologie Intégrative (CBI), CNRS, UPS, University of Toulouse, 31062 Toulouse, France. ${ }^{3}$ Université Paris-Saclay, INRAE, AgroParisTech, GABI, 78350 Jouy-en-Josas, France.

Received: 21 April 2021 Accepted: 30 August 2021

Published online: 14 September 2021

\section{References}

1. Geissmann F, Gordon S, Hume DA, Mowat AM, Randolph GJ. Unravelling mononuclear phagocyte heterogeneity. Nat Rev Immunol. 2010;10(6):45360. https://doi.org/10.1038/nri2784.

2. Nathan C. Neutrophils and immunity: challenges and opportunities. Nat Rev Immunol. 2006:6(3):173-82. https://doi.org/10.1038/nri1785.

3. Kapetanovic R, Fairbairn L, Downing A, Beraldi D, Sester DP, Freeman TC, et al. The impact of breed and tissue compartment on the response of pig macrophages to lipopolysaccharide. BMC Genomics. 2013;14(1):581. https:// doi.org/10.1186/1471-2164-14-581.

4. Ayala-Garcıa MA, Gonzalez Yebra B, Lopez Flores AL, Guanı GE. The major histocompatibility complex in transplantation. J Transp Secur. 2012;2012: 842141-7. https://doi.org/10.1155/2012/842141.

5. Neefjes J, Jongsma ML, Paul P, Bakke O. Towards a systems understanding of MHC class I and MHC class II antigen presentation. Nat Rev Immunol. 2011;11(12):823-36. https://doi.org/10.1038/nri3084.

6. Shiina T, Hosomichi K, Inoko H, Kulski JK. The HLA genomic loci map: expression, interaction, diversity and disease. J Hum Genet. 2009;54(1):1539. https://doi.org/10.1038/jhg.2008.5.

7. Geffrotin C, Popescu CP, Cribiu EP, Boscher J, Renard C, Chardon P, et al. Assignment of $\mathrm{MHC}$ in swine to chromosome 7 by in situ hybridization and serological typing. Ann Genet. 1984;27(4):213-9.

8. Hammer SE, Ho CS, Ando A, Rogel-Gaillard C, Charles M, Tector M, et al. Importance of the major histocompatibility complex (swine leukocyte antigen) in swine health and biomedical research. Annu Rev Anim Biosci. 2020;8(1):171-98. https://doi.org/10.1146/annurev-animal-020518-115014.

9. Rabin M, Fries R, Singer D, Ruddle FH. Assignment of the porcine major histocompatibility complex to chromosome 7 by in situ hybridization. Cytogenet Cell Genet. 1985;39(3):206-9. https://doi.org/10.1159/000132136.

10. Renard C, Hart E, Sehra H, Beasley H, Coggill P, Howe K, et al. The genomic sequence and analysis of the swine major histocompatibility complex. Genomics. 2006;88(1):96-110. https://doi.org/10.1016/j.ygeno.2006.01.004.

11. Renard C, Vaiman M, Chiannilkulchai N, Cattolico L, Robert C, Chardon P. Sequence of the pig major histocompatibility region containing the classical class I genes. Immunogenetics. 2001;53(6):490-50. https://doi.org/1 $0.1007 / \mathrm{s} 002510100348$

12. Cremer T, Cremer M, Dietzel S, Müller S, Solovei I, Fakan S. Chromosome territories - a functional nuclear landscape. Curr Opin Cell Biol. 2006;18(3): 307-16. https://doi.org/10.1016/j.ceb.2006.04.007.

13. Misteli T. Beyond the sequence: cellular organization of genome function. Cell. 2007;128(4):787-0. https://doi.org/10.1016/j.cell.2007.01.028.

14. Fraser J, Williamson I, Bickmore WA, Dostie J. An overview of genome organization and how we got there: from FISH to Hi-C. Microbiol Mol Biol Rev. 2015:79(3):347-72. https://doi.org/10.1128/MMBR.00006-15 .

15. Kempfer $\mathrm{R}$, Pombo A. Methods for mapping 3D chromosome architecture Nat Rev Genet. 2020;21(4):207-26. https://doi.org/10.1038/s41576-019-01 95-2.

16. Lieberman-Aiden $\mathrm{E}$, van Berkum NL, Williams L, Imakaev M, Ragoczy $\mathrm{T}$, Telling $A$, et al. Comprehensive mapping of long-range interactions reveals folding principles of the human genome. Science. 2009:326(5950):289-93. https://doi.org/10.1126/science.1181369. 
17. Nagano T, Lubling Y, Stevens TJ, Schoenfelder S, Yaffe E, Dean W, et al. Single-cell $\mathrm{Hi}-\mathrm{C}$ reveals cell-to-cell variability in chromosome structure. Nature. 2013;502(7469):59-64. https://doi.org/10.1038/nature12593.

18. Ramani V, Deng X, Qiu R, Gunderson KL, Steemers FJ, Disteche CM, et al. Massively multiplex single-cell Hi-C. Nat Methods. 2017;14(3):263-6. https:// doi.org/10.1038/nmeth.4155

19. Ramani V, Deng X, Qiu R, Lee C, Disteche CM, Noble WS, et al. Sci-Hi-C: a single-cell Hi-C method for mapping 3D genome organization in large number of single cells. Methods. 2020;170:61-8. https://doi.org/10.1016/j. ymeth.2019.09.012.

20. Tan L, Xing D, Chang CH, Li H, Xie XS. Three-dimensional genome structures of single diploid human cells. Science. 2018;361(6405):924-8. https://doi.org/10.1126/science.aat5641.

21. Finn EH, Pegoraro G, Brandão HB, Valton AL, Oomen ME, Dekker J, et al. Extensive heterogeneity and intrinsic variation in spatial genome organization. Cell. 2019;176(6):1502-15. https://doi.org/10.1016/j.cell.2019.01.020.

22. Shachar S, Voss TC, Pegoraro G, Sciascia N, Misteli T. Identification of gene positioning factors using high-throughput imaging mapping. Cell. 2015; 16(4):911-23. https://doi.org/10.1016/j.cell.2015.07.035.

23. Forsberg F, Brunet A, Ali TML, Collas P. Interplay of Lamin A and Lamin B LADs on the radial positioning of chromatin. Nucleus. 2019;10(1):7-20. https://doi.org/10.1080/19491034.2019.1570810.

24. Volpi EV, Chevret E, Jones T, Vatcheva R, Williamson J, Beck S, et al. Largescale chromatin organization of the major histocompatibility complex and other regions of human chromosome 6 and its response to interferon in interphase nuclei. J Cell Sci. 2000;113(9):1565-76. https://doi.org/10.1242/ jcs.113.9.1565.

25. Dundr M, Ospina JK, Sung MH, John S, Upender M, Ried T, et al. Actindependent intranuclear repositioning of an active gene locus in vivo. J Cell Biol. 2007;179(6):1095-103. https://doi.org/10.1083/jcb.200710058.

26. Fraser $P$, Bickmore $W$. Nuclear organization of the genome and the potential for gene regulation. Nature. 2007:447(7143):413-7. https://doi. org/10.1038/nature05916.

27. Torabi K, Wangsa D, Ponsa I, Brown M, Bosch A, Vila-Casadesús M, et al. Transcription-dependent radial distribution of TCF7L2 regulated genes in chromosome territories. Chromosoma. 2017;126(5):655-7. https://doi.org/1 0.1007/s00412-017-0629-6.

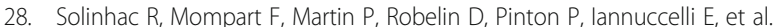
Transcriptomic and nuclear architecture of immune cells after LPS activation. Chromosoma. 2011;120(5):501-20. https://doi.org/10.1007/ s00412-011-0328-7.

29. lannuccelli E, Mompart F, Gellin J, Lahbib-Mansais Y, Yerle M, Boudier T. NEMO: a tool for analyzing gene and chromosome territory distributions from 3D-FISH experiments. Bioinformatics. 2010;26(5):696-7. https://doi. org/10.1093/bioinformatics/btq013.

30. Kusza S, Flori L, Gao Y, Teillaud A, Hu R, Lemonnier G, et al. Transcription specificity of the class Ib genes SLA-6, SLA-7 and SLA-8 of the swine majo histocompatibility complex and comparison with class la genes. Anim Genet. 2011:42(5):510-20. https://doi.org/10.1111/j.1365-2052.2010.02170.x.

31. Lassadi I, Kamgoué A, Goiffon I, Tanguy-le-Gac N, Bystricky K. Differential chromosome conformations as hallmarks of cellular identity revealed by mathematical polymer modeling. PLoS Comput Biol. 2015;11(6):e1004306. https://doi.org/10.1371/journal.pcbi.1004306.

32. Germier T, Kocanova S, Walther N, Bancaud A, Shaban HA, Sellou H, et al. Realtime imaging of a single gene reveals transcription-initiated local confinement. Biophys J. 2017;113(7):1383-94. https://doi.org/10.1016/j.bpj.2017.08.014.

33. Lanctôt C, Cheutin T, Cremer M, Cavalli G, Cremer T. Dynamic genome architecture in the nuclear space: regulation of gene expression in three dimensions. Nat Rev Genet. 2007;8(2):104-15. https://doi.org/10.1038/nrg2041.

34. Boyle S, Gilchrist S, Bridger JM, Mahy NL, Ellis JA, Bickmore WA. The spatial organization of human chromosomes within the nuclei of normal and emerin-mutant cells. J Hum Genet. 2001;10(3):211-9. https://doi.org/10.1 093/hmg/10.3.211

35. Murmann AE, Gao J, Encinosa M, Gautier M, Peter ME, Eils R, et al. Local gene density predicts the spatial position of genetic loci in the interphase nucleus. Exp Cell Res. 2005;311(1):14-26. https://doi.org/10.1016/j.yexcr.2005.07.020.

36. Takizawa T, Meaburn KJ, Misteli T. The meaning of gene positioning. Cell. 2008;135(1):9-13. https://doi.org/10.1016/j.cell.2008.09.026.

37. Finlan LE, Sproul D, Thomson I, Boyle S, Kerr E, Perry P, et al. Recruitment to the nuclear periphery can alter expression of genes in human cells. PLoS Genet. 2008;4(3):e1000039. https://doi.org/10.1371/journal.pgen.1000039.
38. Kumaran Rl, Spector D. A genetic locus targeted to the nuclear periphery in living cells maintains its transcriptional competence. J Cell Biol. 2008;180(1): 51-65. https://doi.org/10.1083/jcb.200706060.

39. Meaburn KJ, Misteli T. Locus-specific and activity-independent gene repositioning during early tumorigenesis. J Cell Biol. 2008;180(1):39-50. https://doi.org/10.1083/jcb.200708204.

40. Lunney JK, Ho CS, Wysocki M, Smith DM. Molecular genetics of the swine major complex, the SLA complex. Dev Comp Immunol. 2009;33(3):362-74. https://doi.org/10.1016/j.dci.2008.07.002

41. Muller $\mathrm{H}$, Gil J, Drinnenberg IA. The impact of centromeres on spatial genome architecture. Trends Genet. 2019;35(8):565-78. https://doi.org/10.1 016/j.tig.2019.05.003

42. Nishimura K, Komiya M, Hori T, Itoh T, Fukagawa T. 3D genomic architecture reveals that neocentromeres associate with heterochromatin regions. J Cell Biol. 2018;218(1):134-49. https://doi.org/10.1083/jcb.201805003.

43. Eckersley-Maslin MA, Spector DL. Random monoallelic expression: regulating gene expression one allele at a time. Trends Genet. 2014;30(6): 237-44. https://doi.org/10.1016/j.tig.2014.03.003.

44. Deng Q, Ramsköld D, Reinius B, Sandberg R. Single-cell RNA seq reveals dynamic, random monoallelic gene expression in mammalian cells. Science. 2014;343(6167):193-6. https://doi.org/10.1126/science.1245316.

45. Jiang $Y$, Zhang NR, Li M. SCALE: modelling allele-specific gene expression by single-cell RNA sequencing. Genome Biol. 2017;18(1):74. https://doi.org/1 0.1186/s13059-017-1200-8

46. Christova R, Jones T, Wu PJ, Bolzer A, Costa-Pereira AP, Watling D, et al. PSTAT1 mediates higher-order chromatin remodeling of the human MHC in response to IFNץ. J Cell Sci. 2007;120(18):3262-70. https://doi.org/10.1242/ jcs.012328.

47. Ottaviani D, Lever E, Mitter R. Reconfiguration of genomic anchors upon transcriptional activation of the human major histocompatibility complex. Genome Res. 2008;18(11):1778-86. https://doi.org/10.1101/gr.082313.108.

48. Jin Y, Gittelman RM, Lu Y, Liu X, Li MD, Ling F, et al. Evolution of DNAase hypersensitive sites in MHC regulatory regions of Primates. Genetics. 2018; 209(2):579-89. https://doi.org/10.1534/genetics.118.301028.

49. Sullivan KE, Reddy ABM, Dietzmann K, Suriano AR, Kocieda VP, Stewart M, et al. Epigenetic regulation of tumor necrosis factor alpha. Mol Cell Biol. 2007:27(14):5147-60. https://doi.org/10.1128/MCB.02429-06.

50. Sklar MD, Tereba A, Chen BD, Walker WS. Transformation of mouse bone marrow cells by transfection with a human oncogene related to c-myc is associated with the endogenous production of macrophage colony stimulating factor 1. J Cell Physiol. 1985;125(3):403-12. https://doi.org/10.1 002/jcp.1041250307.

51. Van Goethem E, Poincloux R, Gauffre F, Maridonneau-Parini I, Le Cabec V. Matrix architecture dictates three-dimensional migration modes of human macrophages: differential involvement of proteases and podosome-like structures. J Immunol. 2010;184(2):1049-61. https://doi.org/10.4049/ jimmunol.0902223.

52. Velten FW, Renard C, Rogel-Gaillard C, Vaiman M, Schrezenmeir J, Chardon P. Spatial arrangement of pig MHC class I sequences. Immunogenetics. 1999:49(11-12):919-30. https://doi.org/10.1007/s002510050575.

53. Rogel-Gaillard C, Bourgeaux N, Billault A, Vaiman M, Chardon P. Construction of a swine BAC library: application to the characterization and mapping of porcine type C endoviral elements. Cytogenet Cell Genet. 1999; 85(3-4):205-11. https://doi.org/10.1159/000015294.

54. Osoegawa K, de Jong PJ, Frengen E, loannou PA. Construction of bacterial artificial chromosome (BAC/PAC) libraries. Curr Protoc Mol Biol. 2001. Chapter 5:Unit 5.9. https://doi.org/10.1002/0471142727.mb0509s55.

55. Yerle M, Goureau A, Gellin J, Le Tissier P, Moran C. Rapid mapping of cosmid clones on pig chromosomes by fluorescence in situ hybridization. Mamm Genome. 1994;5(1):34-7. https://doi.org/10.1007/BF00360565.

56. Bonnet A, Bevilacqua C, Benne F, Bodin L, Cotinot C, Liaubet L, et al. Transcriptome profiling of sheep granulosa cells and oocytes during early follicular development obtained by laser capture microdissection. BMC Genomics. 2011;12(1):417. https://doi.org/10.1186/1471-2164-12-417.

57. Pfaffl MW. A new mathematical model for relative quantification in real-time RT-PCR. Nucleic Acids Res. 2001;29(9):e45-445. https://doi.org/10.1093/nar/2 9.9.e45.

\section{Publisher's Note}

Springer Nature remains neutral with regard to jurisdictional claims in published maps and institutional affiliations. 